\title{
Mechanical and dosimetric quality control for computer controlled radiotherapy treatment equipment
}

\author{
Antoinette V. Thompson, Kwok L. Lam, James M. Balter, Daniel L. McShan, Mary K. \\ Martel, Tamar A. Weaver, Benedick A. Fraass, and Randall K. Ten Haken \\ Department of Radiation Oncology, University of Michigan Medical Center, Ann Arbor, \\ Michigan 48109-0010
}

(Received 18 July 1994; accepted for publication 7 November 1994)

\begin{abstract}
Modern computer controlled radiotherapy treatment equipment offers the possibility of delivering complex, multiple field treatments with minimal operator intervention, thus making multiple field conformal therapy practical. Conventional quality control programs are inadequate for this new technology, so new quality control procedures are needed. A reasonably fast, sensitive, and complete daily quality control program has been developed in our clinic that includes nearly automated mechanical as well as dosimetric tests. Automated delivery of these quality control fields is performed by the control system of the MM50 racetrack microtron, directed by the CCRS sequence processor [D. L. McShan and B. A. Fraass, Proceedings of the XIth International Conference on the use of computers in Radiation Therapy, 20-24 March 1994, Manchester, U.K. (North Western Medical Physics Department, Manchester, U.K., 1994), pp. 210-211], which controls the treatment process. The mechanical tests involve multiple irradiations of a single film to check the accuracy and reproducibility of the computer controlled setup of gantry and collimator angles, table orientation, collimator jaws, and multileaf collimator shape. The dosimetric tests, which involve multiple irradiations of an array of ionization chambers in a commercial dose detector (Keithly model 90100 Tracker $^{\mathrm{TM}}$ System) rigidly attached to the head of the treatment gantry, check the output and symmetry of the treatment unit as a function of gantry and collimator angle and other parameters. For each of the dosimetric tests, readings from the five ionization chambers are automatically read out, stored, and analyzed by the computer, along with the geometric parameters of the treatment unit for that beam. The present work describes in detail these quality control tests that have been implemented in our clinic to help confirm the mechanical and dosimetric consistency of an MM50 racetrack microtron system [Masterson et al., Int. J. Radiat. Oncol. Biol. Phys. 28, 1219-1227 (1994)].
\end{abstract}

Key words: quality control, computer control, racetrack microtron, conformal radiotherapy, CCRS sequence processor

\section{INTRODUCTION}

Three-dimensional radiation therapy treatments often use many complex, non-coplanar fields to achieve better dose homogeneity and conformity to the target volume and less irradiation to healthy tissue. ${ }^{1,2}$ Modern computer controlled treatment equipment has been designed to deliver multiple treatment fields to the patient without the therapists having to enter the room between fields to change gantry and table orientations and beam modifiers. In addition to reducing the number of possible operator errors, treatment delivery should be much faster and more convenient under computer control, allowing more fields to be treated in a shorter amount of time. ${ }^{3}$ During computer-controlled treatment delivery, the therapist initially positions the patient, then monitors the treatment from the control room while the fields are set up, delivered, and monitored by the computer control system. Each computer controlled field is composed of multiple beam portals, or "segments," which can be automatically set up and treated without interruption. Each segment of each field may have a different beam mode and energy, gantry and collimator angle, table orientation, and customized multileaf collimator (MLC) shape.

Conventional quality control programs check the accuracy of the treatment unit itself but have not been designed to ensure the precision of the computer controlled setup of the unit. Our clinic has developed a quality control program that includes nearly automated mechanical as well as dosimetric tests. A mechanical test field consisting of 20 individual mechanical tests checks the reproducibility of computer controlled motions. The dosimetric tests check the output and symmetry of the unit as a function of gantry and collimator angle and other parameters. The present work describes these nearly automated quality control tests that have been implemented in our clinic to help confirm the mechanical and dosimetric consistency of an MM50 racetrack microtron system. ${ }^{4}$

\section{METHODS AND MATERIALS}

Multiple irradiations of a single film are performed to check the accuracy and reproducibility of the computer controlled setup of gantry and collimator angles, table orientation, collimator jaws, and multileaf collimator shape. Automated delivery of a 20 segment field is performed by the control system of the MM50 racetrack microtron, directed by a computer (the CCRS sequence processor ${ }^{5}$ ) which controls the treatment process. Table I lists each of the mechanical tests along with the corresponding machine parameters. To facilitate the analysis of each test, other parameters are held 
TABLE I. Machine parameters for each of the 20 mechanical tests. Starred $\left(^{*}\right)$ segments provide the radiation leakage through the leaves of the MLC to form the two-dimensional grid on the film. (MLC=multileaf collimator, long.=longitudinal.)

\begin{tabular}{|c|c|c|c|c|c|c|c|c|c|c|}
\hline $\begin{array}{l}\text { Seg- } \\
\text { ment }\end{array}$ & $\begin{array}{l}\text { Parameter } \\
\text { tested }\end{array}$ & $\begin{array}{l}\text { Gantry } \\
\text { angle }\end{array}$ & $\begin{array}{l}\text { Collimator } \\
\text { angle }\end{array}$ & $\begin{array}{c}\text { MLC } \\
(L 1+L 2 \times W)\end{array}$ & $\begin{array}{l}\text { Primary } \\
\text { collimators }\end{array}$ & $\begin{array}{l}\text { Table } \\
\text { angle }\end{array}$ & $\begin{array}{l}\text { Table } \\
\text { height }\end{array}$ & $\begin{array}{l}\text { Table } \\
\text { lateral }\end{array}$ & $\begin{array}{l}\text { Table } \\
\text { long. }\end{array}$ & $\begin{array}{c}\text { Monitor } \\
\text { units }\end{array}$ \\
\hline 1 & Table lateral/long. & 0 & 90 & $5 \times 1$ & $2.5+2.5$ & 0 & 0.05 & 12 & 21 & 0.5 \\
\hline 2 & Table lateral/long. & 0 & 90 & $5 \times 1$ & $2.5+2.5$ & 0 & 0.05 & 6 & 28 & 0.5 \\
\hline 3 & Table lateral/long. & 0 & 90 & $5 \times 1$ & $2.5+2.5$ & 0 & 0.5 & 88 & 49 & 0.5 \\
\hline 4 & Table lateral/long. & 0 & 90 & $5 \times 1$ & $2.5+2.5$ & 0 & 0.5 & 94 & 42 & 0.5 \\
\hline 5 & Table lateral/long. & 0 & 90 & $5 \times 1$ & $2.5+2.5$ & 0 & 0.5 & 0 & 35 & 0.5 \\
\hline 6 & ${ }^{*}$ Collimator angle & 0 & 180 & $(2.5+-1.25) \times 15$ & $20.0+20.0$ & 0 & 0.5 & 0 & 35 & 0.5 \\
\hline 7 & Collimator angle & 0 & 270 & $(2.5+-1.25) \times 15$ & $2.5+0.2$ & 0 & 0.5 & 0 & 35 & 0.5 \\
\hline 8 & Collimator angle & 0 & 0 & $(2.5+-1.25) \times 15$ & $2.5+0.2$ & 0 & 0.5 & 0 & 35 & 0.5 \\
\hline 9 & $\begin{array}{l}\text { Collimator \& table } \\
\text { angles }\end{array}$ & 0 & 90 & $\begin{array}{l}(2.5+-1.25) \times 15 \\
(-1.25+2.5) \times 10\end{array}$ & $2.5+2.5$ & 0 & 0.5 & 0 & 35 & 0.5 \\
\hline 10 & Table angle & 0 & 90 & $(-1.25+2.5) \times 10$ & $0.2+2.5$ & 90 & 0.5 & 0 & 35 & 0.5 \\
\hline 11 & Table angle & 0 & 90 & $(-1.25+2.5) \times 10$ & $0.2+2.5$ & 270 & 0.5 & 0 & 35 & 0.5 \\
\hline 12 & *MLC & 0 & 90 & $40 \times(-5+15)$ & $20.0+20.0$ & 0 & 0.5 & 0 & 35 & 0.5 \\
\hline 13 & $* \mathrm{MLC}$ & 0 & 90 & $40 \times(15+-5)$ & $20.0+20.0$ & 0 & 0.5 & 0 & 35 & 0.5 \\
\hline 14 & Primary collimators & 0 & 90 & $40 \times 30$ & $20.0+0.2$ & 0 & 0.5 & 0 & 35 & 0.5 \\
\hline 15 & Primary collimators & 0 & 90 & $40 \times 30$ & $0.2+20.0$ & 0 & 0.5 & 0 & 35 & 0.5 \\
\hline 16 & Gantry angle & 180 & 90 & $(5+0) \times 1$ & $5+0.2$ & 0 & 90.5 & 0 & 29 & 0.5 \\
\hline 17 & Gantry angle & 180 & 90 & $5 \times 1$ & $2.5+2.5$ & 0 & 90.5 & 0 & 29 & 0.5 \\
\hline 18 & Gantry angle & 45 & 90 & $5 \times 1$ & $2.5+2.5$ & 0 & 90.5 & 0 & 29 & 0.5 \\
\hline 19 & Gantry angle & 315 & 90 & $5 \times 1$ & $2.5+2.5$ & 0 & 90.5 & 0 & 29 & 0.5 \\
\hline 20 & Table height & 315 & 90 & $5 \times 1$ & $2.5+2.5$ & 0 & 7.0 & 0 & 29 & 1.0 \\
\hline
\end{tabular}

fixed while a single movement takes place. This procedure uses a standard $35 \times 43 \mathrm{~cm}$ medical $\mathrm{x}$-ray film in a portal localization cassette placed on top of the open portion of the treatment table. The film is sensitive enough to require only 0.5 monitor unit per exposure at about $100 \mathrm{~cm}$ (this is useful because the racetrack microtron has a dose delivery accuracy of 0.1 monitor unit). With the exception of the collimator tests, the other segments produce exposure lines $1.0-1.25 \mathrm{~cm}$ in width and of various lengths for analysis. Displacement of any one of the exposures from its expected position on the film indicates a quantitative change in one of the machine parameters.

The dosimetric tests involve the irradiation of a dose detector containing an array of five parallel-plate ionization chambers. ${ }^{6}$ The five chambers are simultaneously irradiated. One of the ionization chambers is centrally located, while the other four are located $10 \mathrm{~cm}$ from the center along orthogonal axes. The device is controlled and read out using a serial link to the CCRS sequence processor. ${ }^{5}$ To allow testing at multiple gantry angles, the dose detector is rigidly fixed to the head of the treatment gantry so that the ionization cham- bers are at $100 \mathrm{~cm} \mathrm{SAD}$ with acrylic buildup secured on top. This setup checks the consistency of the treatment unit's output for various gantry and collimator angle combinations, and can be helpful in the absence of a linear scanner. Because of the amount of time necessary to manually set up a large number of fields, dosimetric monitoring as extensive as that described here is only possible under computer control. Table II lists the geometric parameters of each of the dosimetric tests. Large open fields are checked near isocenter for 16 combinations of collimator and gantry angles. Three wedged beams are checked at four gantry angles and a fixed collimator angle.

\section{RESULTS AND DISCUSSION}

\section{A. Mechanical tests}

Figure 1 shows the mechanical test film which is obtained by the automated irradiation of a 20 segment field. The first five segments check the table lateral and longitudinal positioning. A $1.0 \mathrm{~cm}$ error in table position (in either direction) results in a $1.0 \mathrm{~cm}$ displacement of the exposure line on the

TABLE II. Machine parameters for each of the dosimetric tests. The seven segments shown are repeated for gantry angles 90,180 , and 270 for a total of 28 segments in all. (MLC=multileaf collimator.)

\begin{tabular}{lcccccc}
\hline \hline $\begin{array}{l}\text { Seg- } \\
\text { ment }\end{array}$ & $\begin{array}{c}\text { Photon } \\
\text { energy }\end{array}$ & $\begin{array}{c}\text { Gantry } \\
\text { angle }\end{array}$ & $\begin{array}{c}\text { Collimator } \\
\text { angle }\end{array}$ & Wedge & $\begin{array}{c}\text { MLC } \\
(L \times W)\end{array}$ & $\begin{array}{c}\text { Primary } \\
\text { collimators }\end{array}$ \\
\hline 1 & $10 \mathrm{MV}$ & 0 & 90 & 0 & $25 \times 25$ & $12.5+12.5$ \\
2 & $10 \mathrm{MV}$ & 0 & 180 & 0 & $25 \times 25$ & $12.5+12.5$ \\
3 & $10 \mathrm{MV}$ & 0 & 270 & 0 & $25 \times 25$ & $12.5+12.5$ \\
4 & $10 \mathrm{MV}$ & 0 & 0 & 0 & $25 \times 25$ & $12.5+12.5$ \\
5 & $10 \mathrm{MV}$ & 0 & 90 & 15 & $19.8 \times 40$ & $9.9+9.9$ \\
6 & $10 \mathrm{MV}$ & 0 & 90 & 45 & $19.8 \times 40$ & $9.9+9.9$ \\
7 & $10 \mathrm{MV}$ & 0 & 90 & 60 & $19.8 \times 40$ & $9.9+9.9$ \\
\hline \hline
\end{tabular}




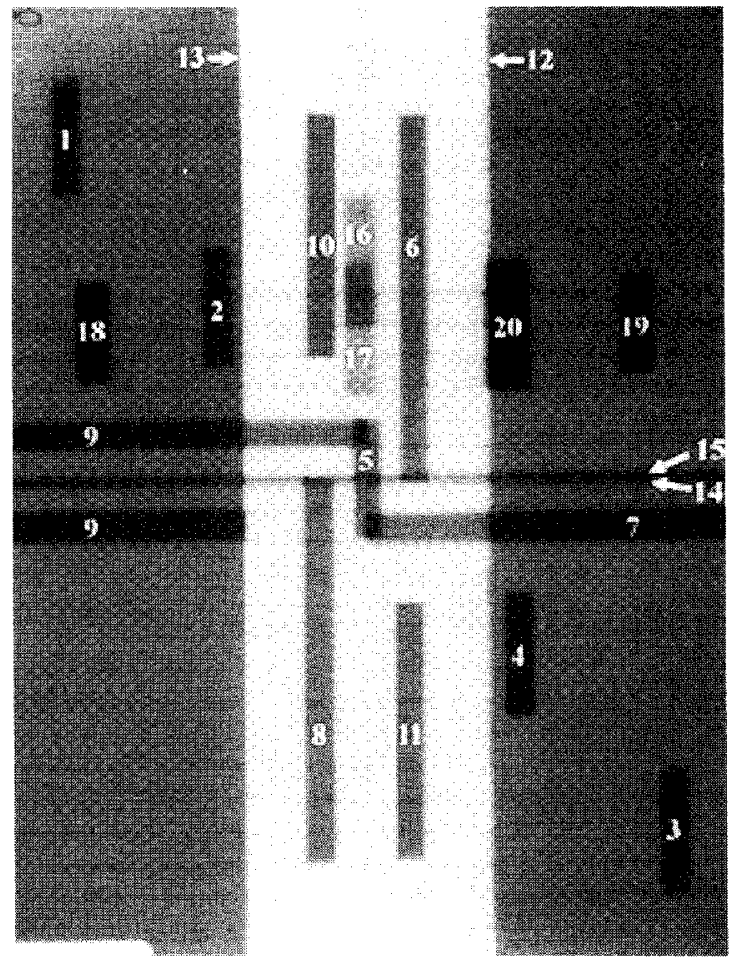

FIG. 1. Mechanical test film. Each numbered exposure corresponds to a different set of machine parameters as listed in Table I.

film from its expected position. The next six segments use off-center exposure lines of different lengths to check collimator and table rotation. The outer edges of these exposures are $15.0 \mathrm{~cm}$ from the point of rotation, so that a $1 \mathrm{deg}$ error in collimator or table angle appears as a $2.6 \mathrm{~mm}$ lateral shift of the line at this outer edge. The next three segments check the positioning of the jaws and multileaf collimator at the ends of their ranges of motion $(0.2 \mathrm{~cm}$ from midline for the block collimator jaws, and $5.0 \mathrm{~cm}$ across midline for the MLC). Since the top of the block collimator is $36 \mathrm{~cm}$ from the source, a $1.0 \mathrm{~mm}$ error in the block collimator jaw position is magnified to a $2.8 \mathrm{~mm}$ displacement of the exposure line at isocenter. Similarly, since the top of the MLC is $60 \mathrm{~cm}$ from the source, a $1.0 \mathrm{~mm}$ positioning error magnifies to a $1.7 \mathrm{~mm}$ displacement of the exposure line. The next two segments verify gantry angle setup at $45 \mathrm{deg}$ from the vertical downward position. With the film at $10 \mathrm{~cm}$ above isocenter, a $1 \mathrm{deg}$ error in gantry angle results in a $3.6 \mathrm{~mm}$ lateral displacement of the exposure line. Gantry angle setup is also tested at the clockwise and counterclockwise limits of the computer controlled motion. Here, a $1 \mathrm{deg}$ error in a gantry angle results in a $1.8 \mathrm{~mm}$ displacement of the exposure. Finally, table height setup is tested with the gantry angled 45 deg from the vertical downward position so that an error in table height results in an equal displacement of the exposure line laterally; i.e., a $1.0 \mathrm{~mm}$ error in table height results in a $1.0 \mathrm{~mm}$ lateral displacement of the exposure line. In addition, a few of the segments irradiated with the MLC mostly closed are done with the block collimator jaws open so that the leakage between the leaves forms a grid on the film which can be used to align films for comparison.

The time required to perform the 20 segment mechanical

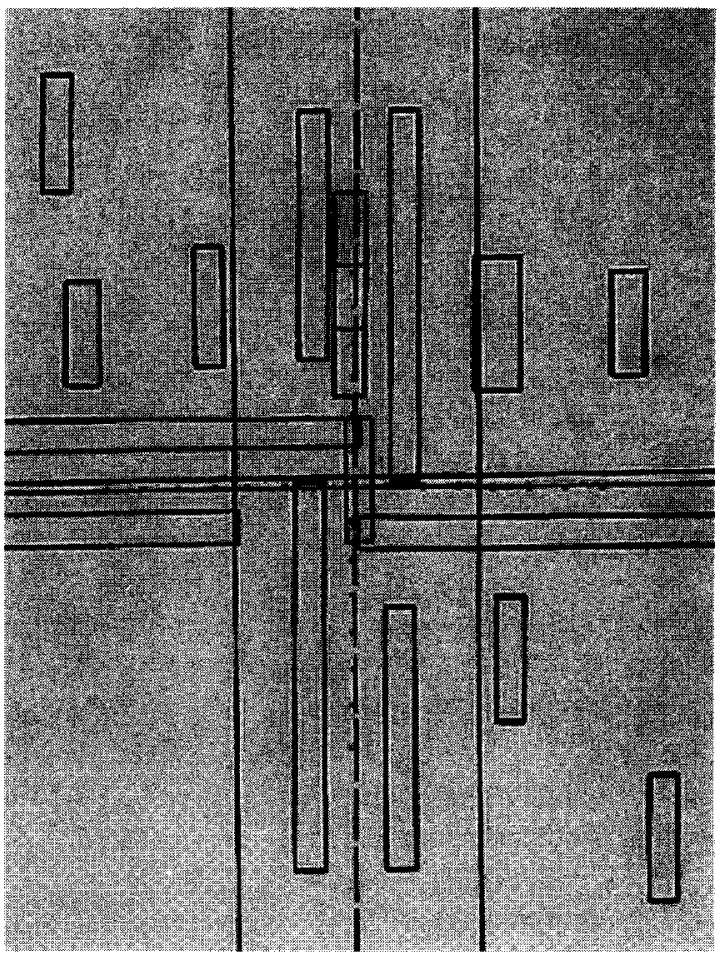

FIG. 2. Template used to check mechanical test film daily.

field is approximately $20 \mathrm{~min}$. A reduction to $15 \mathrm{~min}$ was obtained by eliminating two of the five lateral/longitudinal table movements, decreasing the angle of the table rotations, and moving both jaws of the block collimator toward the center of the field simultaneously.

Due to the high sensitivity of this method to small displacement errors, the daily films can be quickly checked with a template like the one shown in Fig. 2. This templatematching method easily allows identification of positioning errors of approximately $1.0 \mathrm{~mm}$, or a third of a degree. Disagreement larger than $1.0 \mathrm{~mm}$ or $0.5 \mathrm{deg}$ are investigated. Further analysis can be performed by aligning the film with another film or by digitizing the film and using computerbased analysis. If an imager were used, the field could be checked automatically and stored on computer disk. Note however that the imager would have to be placed on the table. In 1.5 years of daily clinical use on the racetrack microtron, only a few errors have been detected: 1) a $2.0 \mathrm{~mm}$ error in table lateral position, and 2) a $1.0 \mathrm{deg}$ miscalibration of the secondary collimator angle readout at the end of its range.

\section{B. Dosimetric tests}

The dosimetric tests are performed automatically also. For each segment, readings from the five ionization chambers are automatically read out and stored by the computer, along with the geometric parameters of the treatment unit for that segment. These data can be analyzed by computer, or simply printed out and inspected manually. Our clinic uses an automatic analysis program that calculates the temperaturepressure correction factor and displays tables of raw readings and corrected readings for all five chambers for each segment. It also analyzes the four outer chamber readings for 
radial and transverse symmetry and flags those that are not within a $2 \%$ tolerance. Finally, the program compares the corrected center chamber readings to those in a base file, which consists of a "standard" set of readings taken at the time of the most recent output calibration, and flags any output readings that are outside a $2 \%$ tolerance.

The time required to run all 28 dosimetric checks is about $50 \mathrm{~min}$. This very extensive test was initially designed to completely document the behavior of the one photon beam which was in clinical use on our racetrack microtron system, since it was a new type of machine. Since then, the reliable behavior of the machine and the introduction of other beams for clinical use has caused numerous modifications to the test design. The test now consists of a standard subset of checks which is performed daily for each beam. The time required to perform the daily dosimetric testing is now approximately $25 \mathrm{~min}$ for all six beams. The combined time for the mechanical and dosimetric tests totals $45 \mathrm{~min}$, which is comparable to conventional daily quality control programs.

\section{CONCLUSIONS}

Computer controlled radiotherapy treatment equipment is designed to provide higher precision and greater accuracy of dose delivery by eliminating some of the possible human errors. These machines can also substantially reduce the amount of time required to treat large numbers of fields with different table, gantry, and collimator orientations and beam modifiers. However, since there has been little clinical use of fully computer controlled treatment delivery, quality control procedures for these kinds of machines and delivery techniques are not available. Current quality control programs are inadequate for this new technology, so new quality control procedures for these treatment units are needed. In this work, a reasonably fast, sensitive, and complete quality control program has been presented. This procedure is used to confirm the mechanical and dosimetric consistency of a computer controlled radiotherapy treatment unit. Over the last year and a half, this program has shown the reliable performance of our MM50 racetrack microtron system over a wide range of parameters used for radiotherapy treatments in our department.

\section{ACKNOWLEDGMENT}

Supported in part by US-PHS NIH Grant No. P01CA59827.

${ }^{\prime}$ C. C. Ling, C. Burman, C. S. Chui, A. Jackson, G. J. Kutcher, S. Leibel, T. LoSasso, G. Mageras, R. Mohan, E. Yorke, and Z. Fuks, "Perspectives of Multidimensional Conformal Radiation Treatment," Radiother. Oncol. 29, 129-139 (1993).

${ }^{2} \mathrm{Q}$. Wang and A. T. Redpath, "Computer Controlled Dynamic Conformal Therapy," in Proceedings of the XIth International Conference on The Use of Computers in Radiation Therapy, 20-24 March 1994, Manchester, U.K. (North Western Medical Physics Department, Manchester, U.K. 1994), pp. 212-213.

${ }^{3}$ A. S. Lichter and R. K. Ten Haken, "Three-Dimensional Treatment Planning and Conformal Radiation Dose Delivery," in Principles \& Practice of Oncology Updates, Vol. 8, NO. 5 (J. B. Lippincott Company, Philadelphia, PA, 1994).

${ }^{4}$ M. E. Masterson, G. S. Mageras, T. LoSasso, E. Joreskog, L. G. Larsson, B. Tsirakis, R. Febo, R. Mohan, C. C. Ling, S. A. Leibel, Z. Fuks, and G. J. Kutcher, "Preclinical Evaluation of the Reliability of a $50 \mathrm{MeV}$ Racetrack Microtron,” Int. J. Radiat. Oncology Biol. Phys. 28, 1219-1227 (1994).

${ }^{5}$ D. L. McShan and B. A. Fraass, "UM-CCRS/SP: Sequence Processor for Computer Controlled Radiotherapy Treatment Delivery," in Proceedings of the XIth International Conference on The Use of Computers in Radiation Therapy, 20-24 March 1994, Manchester, U.K. (North Western Medical Physics Department, Manchester, U.K., 1994), pp. 210-211

${ }^{6}$ Keithley Model 90100 Tracker ${ }^{\mathrm{TM}}$ System. 